\title{
Kemik Berelenmesi Medikolegal Süreçte Kırık Olarak Değerlendirilmeli mi? Olgu Sunumu
}

\author{
Should Bone Bruising be Considered as A Fracture in Medicolegal Process? A Case Report
}

\author{
Burçin Gürbeden, Devrim Sertaç Özkan, Mehmet Hakan Özdemir
}

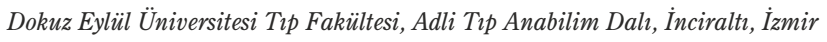

‘Bu çalışma 23-26 Nisan 2014 tarihlerinde K.K.T.C.'de düzenlenen 11. Adli Bilimler Kongresi’nde sözel bildiri olarak sunulmustur.

\section{Özet}

Kemik berelenmesi, travma sonrası kemiğin subkondral alanında oluşan düzensizlik, ödem ve kanama ile karakterize mikrotrabeküler kırıklardır. Olay medulla ile sinırlı olduğundan direk grafiler ile tespit edilemez. Tanıda Manyetik Rezonans Görüntüleme (MRG) önemlidir.

Olgumuz 23 yaşındaki erkek, geçirdiği araç içi trafik kazasında să̆ dizini ön konsole çarpmış, bir üniversite hastanesinde izlem sonrası taburcu edilmiş, ağrı şikayetinin geçmemesi üzerine 1 ay sonra çekilen MRG'de femur $1 / 3$ distalde diffüz yamalı tarzda intratrabeküler düzensizlik ve intramedüller kemik iliği ödem sahaları, tibia lateral subkondral yüzde de fokal intramedüller kemik iliği ödemi saptanmıștır.

$\mathrm{Bu}$ çalışmada, MRG incelemesi ile sağ femur distalinde kemik berelenmesi tanısı konan, "TCK'da Tanımlanan Yaralanma Suçlarının Adli Tıp Açısından Değerlendirmesi” kılavuzunda yer almayan bu kavrama dikkat çekmek ve kılavuza yeni bir değerlendirme kriteri önermek amaçlanmıştır.

Anahtar Kelimeler: Kemik kırı̆̆ı, Kemik berelenmesi, Medikolegal değerlendirme.

\section{Giriş}

Kemik kırı̆̆ı, dıştan veya içten etki eden faktörlerle korteksi de içerecek şekilde kemik dokusunda anatomik bütünlüğün ve devamlılı̆̆ın bozulması durumudur (1) Kemik berelenmesi ise travma sonrası kemikte subkondral alanda oluşan düzensizlik, ödem ve kanama ile karakterize mikrotrabeküler düzensiz kırıklar olarak kabul edilmektedir $(2,3)($ Resim 1-2).

Kemik berelenmesi çoğu travmada olduğu gibi şişlik ve ağrı semptomları ile bulgu verir. Haftalar ya da aylar boyu sürebilen şiddetli ağrı ile karakterize olduğu ve şişliğin kemiği çevreleyen cilt, kas ve bağ gibi yumuşak dokularda göründüğü, şişliğe renk değişikliğinin de eşlik ettiği bilinmektedir. Sıklıkla eklem içi yaralanmalarıyla birliktedir (4)

Sorumlu Yazar: Prof.Dr. Mehmet Hakan Özdemir

Dokuz Eylül Üniversitesi Tip Fakültesi.

Adli Tip Anabilim Dalı, Inciraltı, Izmir

E-mail: hakan.ozdemir@deu.edu.tr

\section{Abstract}

Bone bruising is a microtrabecular fractures characterized with edema, hemorrhage and irregularity occured in subcondral area of bone. Because of that it is limited with medulla, it can't be detected by direct graphies. Magnetic resonance imaging (MRI) is important in diagnosis.

In our case, our patient is a 23 years old male, he hit his right knee to the front console of car in a traffic accident, he was discharged from a university hospital after medical follow up, in MRI after 1 month later because of that his pain didn't heal, intratrabecular irregularity in a diffuse patchy pattern and areas of intramedullary bone marrow edema were determined in distal $1 / 3$ of femur. Focal intramedullary bone marrow edema determined in subcondral face of lateral tibia.

In this study, it was aimed to attract attention to a concept that diagnosed as a bone bruising in distal of right femur by MRI examination and don't take place in guide of "Evaluation of Injuries Defined In Turkish Criminal Code” and to suggest a new evaluation criteria to the guide.

Keywords: Bone Fracture, Bone Bruise, Medikolegal Assessment.

Kemik berelenmelerinin direkt grafilerde tespit edilememesinin nedeni yaralanmanın medulla ile sınırlı olması ve korteksin sağlam olmasıdır (2). Manyetik rezonans görüntülemenin (MRG) bu gizli yaralanmaların teşhisinde çok etkili bir yöntem olduğu belirtilmektedir (2).

Akut diz yaralanmalarından sonra Lynch ve ark. 434 hastanın \%20'sinde, Terzidis ve ark. ise 255 hastanın \%27.8'inde MRG ile gizli kemik berelenmesi tespit etmiştir $(5,6)$.

Roemer ve Bohndorfun yaptığı retrospektif bir çalışmada, diz ekleminde akut travma sonrası meydana gelen uzun süreli kemik sekellerinin MRG ile değerlendirilmesi sonucu kemik berelenmesi prevelansının 176 hastanın \%72'si olduğu, akut posttravmatik kemik berelenmesinin çoğu hastada 2 yıl sonra tamamen kaybolduğu belirtilmektedir (7).

Kemik berelenmesi olan hastalarda efüzyon miktarının ve süresinin daha fazla olduğu, ağrı skorlarının arttığı ve klinik düzelmenin (ağrısız yürüme, normal eklem hareket sınırı) uzadığ 1 bildirilmiştir. Bu hastalarda rehabilitasyon sırasında da daha fazla sorunla karşılaşılmaktadır (7). Travmanın şiddetine 
göre kemik berelenmelerin ortalama 6-12 hafta içinde gerilediği, ancak bu sürenin 2 yıla kadar uzayabildiği belirtilmiştir $(7,9)$.

Kemik berelenmesinin ayırıcı tanısında travma dışında osteoporoz, osteomalazi, kemik iliği ödemi sendromu, glukokotikoid kullanımı, tümör, paget düşünülmelidir (10-14).

Subkondral kemiğe yakın olan kemik berelenmesi sonrasında çeşitli osteokondral lezyonlar da (kıkırdakta incelme, subkortikal skleroz, osteokondral kırık gibi) gözlenebildiği bildirilmiştir (15-17).

$\mathrm{Bu}$ çalışmada, MRG incelemesi ile sağ femur distalinde kemik berelenmesi tanısı konan, "TCK' da tanımlanan yaralanma suçlarının Adli tıp açısından değerlendirmesi” kılavuzunda yer almayan bu kavrama dikkat çekmek ve kılavuza yeni bir değerlendirme kriteri önermek amaçlanmıştır.

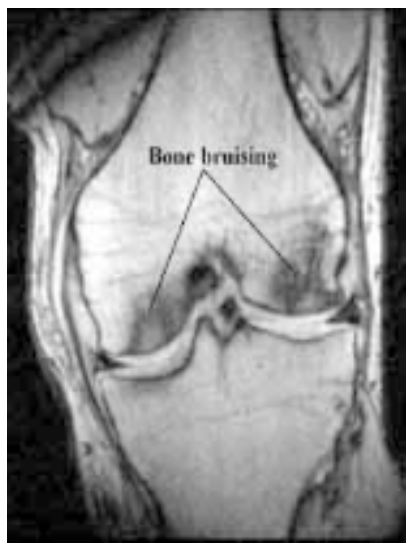

Resim1.

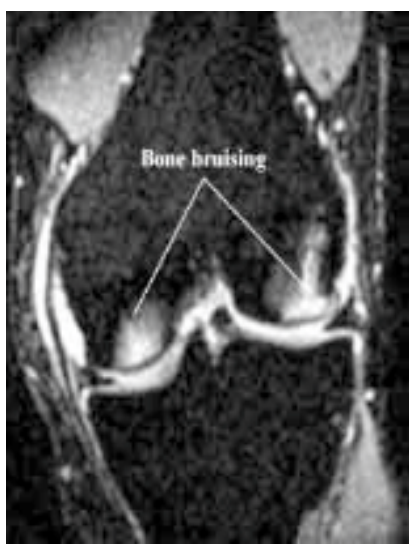

Resim2.
Resim 1-2. Kemik berelenmesinin manyetik rezonans görüntüleri (3)

\section{Olgu Sunumu}

Olgumuz 23 yaşındaki erkek, bilinen hastalığı yok. Aralık 2011 tarihinde anabilim dalımıza beş ay önce geçirdiği araç içi trafik kazası nedeniyle medikolegal değerlendirmesinin yapılması amacıyla başvurdu. Hasta verdiği öyküde kazada să̆ dizini ön konsole çarptığını, bir üniversite hastanesi acil servisinde 4 saatlik izlem sonrası taburcu edildiğini, ağrı şikayetinin geçmemesi üzerine bir ay sonra özel bir sağlık kuruluşunda MRG çektirdiğini, grafide femur 1/3 distalmedialde daha belirgin olmak üzere diafizden metafizoepifizer düzeye dek uzanan diffüz yamalı tarzda intratrabeküler düzensizlik ve intramedüller kemik iliği ödem sahaları, tibia lateral subkondral yüzde de fokal intramedüller kemik iliği ödemi, mevcut olduğu belirtilmiştir.

Halen sağ diz ağrısı devam eden hastadan istenen Ortopedi ve Travmatoloji Anabilim Dalı konsültasyonuna verilen yanitta; hastanın mevcut anamnez, fizik muayene, radyolojik bulguları sonucu mevcut şikayetlerinin geçirilmiş travma ve/veya kronik dejeneratif süreç ile ilişkili olabileceği belirtilmiştir.

Olgumuzun medikolegal değerlendirme raporunda, meydana gelen yaralanmanın basit tıbbi müdahale ile giderilemeyeceği şeklinde tıbbi kanaat belirtilmiştir.

\section{Tartışma ve Sonuç}

Wilson ve ark. standart radyografilerin nonspesifik osteopeni ya da normal olarak değerlendirildiği diz ve kalça ağrılı bir grup hastadaki çalışmalarında; MRG görüntülerinde kemik iliğinde tam tanımlanamamış hiperintensite alanları tanımlamışlar ve bu görünümleri daha net bir terminoloji olmadığı için kemik iliği ödemi olarak adlandırılmışlardır (18).

Patologlar ise kemik iliğindeki bu değişikliklerin kan toplanması, ödem, reaktif hiperemiyi arttırdığını ve subkondral kemikteki trabeküllerde kemik iliği sinyal yoğunluğunu değiştiren mikrofraktürler olabileceğini öne sürmektedir (19).

Zamanla kemik iliği ödemi terimi durumun travmatik doğasını yansıtmak için yerini kemik berelenmesi terimine bırakmıştır. MRG çalışmalarının özgünlük kazanması ile kemik berelenmesi tanımının yalnızca tipik MRG bulguları gösteren subkondral lezyonlar için kullanıldığ 1 gözlenmektedir $(20,21)$. Olgumuzda da kemik berelenmesi tanısı MRG yöntemi ile konulmuştur.

Kemik berelenmesindeki bulgular kistik lezyonlar ve atravmatik durumlardan ayırt edilmelidir $(19,20)$. Kemik iliği ödeminin patofizyolojisi halen nonspesifiktir ve farklı olgularda ayrımı zor olabilir. Özellikle, osteokondritis dissekans, dizin spontan osteonekrozu ve idiopatik geçici kemik iliği sendromundan ayırt etmek zordur, çünkü gelişimlerinde iskemik ve mikrotravmatik faktörler beraber katkı sağlar (22).

Johnson ve ark. tarafindan yapılan diz yaralanması olan 40 hastada yapılan prospektif bir çalışmada 20 kişilik bir grupta kemik berelenmesi izlenirken diğer 20 kişilik grupta kemik berelenmesinin olmadığ 1 , kemik berelenmesi olan grupta daha fazla oranda eklem içinde efüzyon olduğu, ağrı skorunun kemik berelenmeli olgularda daha yüksek olduğu belirlenmiştir (8).

Mankin'in çalışmasında ise künt travma sonucu subkondral mikrokırıkların önceki normal kemiğe göre daha sert bir kemik yapı ile iyileştiği, subkondral kemikte meydana gelen azalmanın eklemdeki kartilajda daha fazla yük oluşturarak ilerleyici dejenerasyona yol açabileceği belirtilmiştir (23). Olgumuzda ise benzer şekilde geçirdiği araç içi trafik kazasından 5 ay sonra anabilim dalımızda yapılan muayenesinde sağ dizdeki ağrı şikayetinin devam ettiği belirlenmiştir. 
Travma sonras 1 hastalarin medikolegal değerlendirmesinde kemik hasarlarının saptanması önemli kriterlerden biridir. Travma sonrası çekilen direk grafilerde kırık görülmemesi kemik dokusunda travmatik değişim olmadı̆̆ı anlamına gelmemektedir. Hastanın ağrısının şiddetli ve uzun olduğu durumlarda MRG ile kemik berelenmesi tanısının ekarte edilmesi gerekmektedir.

Ülkemizde kişilerin travmaya bağlı oluşan lezyonlarının ağırlığının adli tıbbi olarak değerlendirilmesinde, Adli Tıp Kurumu Başkanlığı, Adli Tıp Uzmanları Derneği ve Adli Tıp Derneği tarafından hazırlanan "TCK' da Tanımlanan Yaralanma Suçlarının Adli Tıp Açısından Değerlendirmesi” kılavuzu kullanılmaktadır. Kılavuzu incelediğimizde kemik trabekül kırı̆̆ı (mikrokırık) veya kemik berelenmesi kavramlarının yer almadığını gözlemledik.

Kemik berelenmesinin hastanın uzun süre günlük işlevlerini etkileyecek potansiyelde bir yaralanma yol açtığı göz önünde bulundurulduğunda; Medikolegal değerlendirme de kemik berelenmesi kavramının, kılavuzdaki skorlama sistemleri içinde "kemik kırıkları bölümümde" ve "basit tıbbi müdahale ile giderilemeyecek nitelikte" yaralanma kapsamında ele alınmasının uygun yaklaşım olacağ düşüncesindeyiz.

\section{Kaynaklar}

1. Tuncel As N. Fasiyal kırık etyolojilerinin retrospektif analizi. İstanbul, Sağlık Bakanlığı Haydarpaşa Numune Eğitim ve Araştırma Hastanesi Plastik ve Rekonstruktif Cerrahi Kliniği. Uzmanlık Tezi, 2008:5.

2. Gönç U, Kayaalp A, Irgıt K. Dizde gizli kemik yaralanmaları. Acta Orthop Traumatol Turc 2007;41:98-104.

3. http://www.dmi-uk.com/knee_bruise.php (Erişim tarihi: 02.03.2015)

4. http://www.md-health.com/Bone-Bruise.html (Erişim tarihi: 20.06.2014).

5. Lynch TC, Crues JV 3rd, Morgan FW, Sheehan WE, Harter LP, Ryu R. Bone abnormalities of the knee: prevalence and significance at MR imaging. Radiology 1989;171:761-6.

6. Terzidis IP, Christodoulou AG, Ploumis AL, Metsovitis SR, Koimtzis M, Givissis P. The appearance of kissing contusion in the acutely injured knee in the athletes. Br J Sports Med 2004;38:592-6.

7. Roemer FW, Bohndorf K. Long-term osseous sequelae after acute trauma of the knee joint evaluated by MRI. Skeletal Radiol 2002;31:615-23.
8. Johnson DL, Bealle DP, Brand JC Jr, Nyland J, Caborn DN. The effect of a geographic lateral bone bruise on knee inflammation after acute anterior cruciate ligament rupture. Am J Sports Med 2000;28:152-5.

9. Miller MD, Osborne JR, Gordon WT, Hinkin DT, Brinker MR. The natural history of bone bruises. A prospective study of magnetic resonance imaging-detected trabecular microfractures in patients with isolated medial collateral ligament injuries. Am J Sports Med 1998;26:15-9.

10. Reginato AJ, Coquia JA. Musculoskeletal manifestations of osteomalacia and rickets. Best Pract Res Clin Rheumatol 2003;17(6):1063-1080.

11. Metabolik kemik hastalıkları. Türkiye Endokrinoloji ve Metabolizma Derneği. Ankara 2013.

12. Menkes CJ. Epidemiology and etiology of osteomalacia. http://www.uptodate.com.

13. Liberman UA. Disordes in vitamin D action. http://www.endotext.org.

14. Pereira RMR, Carvalho JF, Canalis E. Glucocorticoid-induced osteoporosis in rheumatic diseases. Clinics. 2010;65(11):11971205.

15. Vellet AD, Marks PH, Fowler PJ, Munro TG. Occult posttraumatic osteochondral lesions of the knee: prevalence, classification, and short-term sequelae evaluated with MR imaging. Radiology 1991;178:271-6.

16. Faber KJ, Dill JR, Amendola A, Thain L, Spouge A, Fowler PJ. Occult osteochondral lesions after anterior cruciate ligament rupture. Six-year magnetic resonance imaging followup study. Am J Sports Med 1999;27:489-94.

17. Costa-Paz M, Muscolo DL, Ayerza M, Makino A, Aponte-Tinao L. Magnetic resonance imaging follow-up study of bone bruises associated with anterior cruciate ligament ruptures. Arthroscopy 2001;17:445-9.

18. Wilson AJ, Murphy WA, Hardy DC, Totty WG. Transient osteoporosis: transient bone marrow edema? Radiology. 1988;167(3):757-760.

19. Mink JH, Deutsch AL. Occult cartilage and bone injuries of the knee: detection, classification, and assessment with MR imaging. Radiology. 1989;170(3, pt 1):823-829.

20. Roemer FW, Frobell R, Hunter DJ, et al. MRI-detected subchondral bone marrow signal alterations of the knee joint: terminology, imaging appearance, relevance and radiological differential diagnosis [published online ahead of print March 31, 2009]. Osteoarthritis Cartilage.

21. Hunter DJ, Lo GH, Gale D, Grainger AJ, Guermazi A, Conaghan PG. The reliability of a new scoring system for knee osteoarthritis MRI and the validity of bone marrow lesion assessment: BLOKS (Boston Leeds Osteoarthritis Knee Score). Ann Rheum Dis. 2008;67(2):206-211.

22. Yamamoto T, Bullough PG. Spontaneous osteonecrosis of the knee: the result of subchondral insufficiency fracture. J Bone Joint Surg Am. 2000;82(6):858-866.

23. Mankin HJ. The response of articular cartilage to mechanical injury. J BoneJoint Surg (Am) 1982;64:460-6. 